\title{
Analysis of $\mathrm{COCH}$ and TNFA Variants in East Indian Primary Open-Angle Glaucoma Patients
}

\author{
Subhadip Chakraborty, ${ }^{1}$ Suddhasil Mookherjee, ${ }^{1,2}$ Abhijit Sen, ${ }^{3}$ and Kunal Ray ${ }^{1,4}$ \\ ${ }^{1}$ Molecular \& Human Genetics Division, CSIR-Indian Institute of Chemical Biology, 4 Raja S. C. Mullick Road, \\ Kolkata 700 032, India \\ ${ }^{2}$ NEI/NIH, 6 Center Drive, Room 306 MSC 0610, Bethesda, MD 20892, USA \\ ${ }^{3}$ Dristi Pradip, 385 Jodhpur Park, Kolkata 700 068, India \\ ${ }^{4}$ Academy of Scientific and Innovative Research, Anusandhan Bhavan, 2 Rafi Marg, New Delhi 110 001, India
}

Correspondence should be addressed to Kunal Ray; kunalray@gmail.com

Received 28 April 2013; Revised 18 July 2013; Accepted 23 July 2013

Academic Editor: Marcela Votruba

Copyright (C) 2013 Subhadip Chakraborty et al. This is an open access article distributed under the Creative Commons Attribution License, which permits unrestricted use, distribution, and reproduction in any medium, provided the original work is properly cited.

\begin{abstract}
Glaucoma represents a heterogeneous group of optic neuropathies with a complex genetic basis. It is the second-largest cause of blindness in the world that reduces vision without warning and often without symptoms. Among 3 major subtypes of glaucoma, primary open-angle glaucoma (POAG) is the most common form. The focus of this study is to understand the molecular basis of the disease among Indian patients with respect to two genes, Cochlin $(\mathrm{COCH})$ and tumor necrosis factor alpha (TNFA), selected based on reports of possible association with POAG. The genes were screened in patients and controls by PCR and direct sequencing. Although two novel changes $(-450 \mathrm{C} / \mathrm{T}$ and $-79 \mathrm{G} / \mathrm{G})$ were identified in the $5^{\prime}$ upstream region of $\mathrm{COCH}$, no causal variant could be identified in either gene. $-450 \mathrm{C} / \mathrm{T}$ was detected in 3 patients and 2 controls and $-79 \mathrm{G} / \mathrm{C}$ in a single patient. Further, we did not observe significant association with the promoter SNPs of TNFA that had been previously reported to be associated with POAG pathogenesis. Thus, our study suggests lack of association of both $\mathrm{COCH}$ and TNFA with POAG pathogenesis.
\end{abstract}

\section{Introduction}

Glaucoma is a heterogeneous group of optic neuropathies characterized by typical visual field loss, often associated with increased intraocular pressure (IOP). It is the second leading cause of blindness after cataract and a silent killer of vision; often cases result in excessive loss of vision without any signs or symptoms. According to the latest estimate, 67 million people are visually impaired due to glaucoma worldwide, and among them 3.1 million are blind [1].

Among different subtypes of glaucoma, primary openangle glaucoma (POAG) is the most common form. POAG is a multifactorial complex disorder in which both environmental and genetic factors precipitate the disease. It has been suggested that $72 \%$ of POAG cases have some familial component, but on rare occasions the disease follow a Mendelian pattern of inheritance [2].

The complexity of POAG has been reviewed recently in detail [3-7]. There are 33 chromosomal loci that have been mapped through linkage analysis for POAG. However, only five underlying genes have been identified so far: Myocilin (GLC1A) [8] Optineurin (GLC1E) [9], WD repeat domain 36 (GLC1G) [10], NTF4 (GLC1O) [11], and ASB10 (GLC1F) [12] . In addition, candidate gene studies provide evidence for at least 30 POAG susceptibility genes. However, most studies demonstrate association in single population groups, and in some cases conflicting results have been reported in studies done on the same population. Therefore, it is difficult to judge whether the variations observed in these association studies are due to population difference, sample size, study design, or clinical heterogeneity between different cohorts of patients.

Proteomic studies and expression analyses of the trabecular meshwork (TM) from patients with POAG and agematched controls implicated Cochlin as a potential contributing factor to glaucoma pathogenesis [13-15]. Cochlin is a secretory extracellular matrix (ECM) protein of unknown function. Cochlin deposits were subsequently detected in glaucomatous, but not in control TM. Additionally, older 
glaucomatous TM was found to contain higher levels of Cochlin deposition. Cochlear Cochlin deposition is normally associated with an autosomal dominant nonsyndromic auditory and vestibular disorder (DFNA9) where misfolded Cochlin is thought to contribute to the formation of cochlear deposits. It was found that Cochlin deposits with mucopolysaccharide (MPS) develop in the TM of patients with POAG and glaucomatous DBA/2J mice [16]. This could potentially obstruct aqueous humor outflow and ultimately lead to elevated IOP. In both humans and mice, an agerelated increase in Cochlin deposition was observed, which was consistently absent in normal TM tissues.

Tumor necrosis factor-alpha (TNF- $\alpha$ ) is a proinflammatory cytokine with multiple functions in the immune response. Since its initial discovery as a serum factor causing tumor necrosis [17], this potent immune-modulator has also been implicated in a wide spectrum of human diseases including sepsis, diabetes, cancer, collagen tissue diseases, and neurodegenerative diseases [18-20]. In recent years, it has been suggested that TNF- $\alpha$ may participate in apoptotic death of retinal ganglion cells in glaucoma patients [21, 22]. An upregulation of TNF- $\alpha$ and TNF-receptor 1 has also been observed in optic nerve heads and retinal sections of glaucomatous eyes [23]. Furthermore, an in vitro study has shown that glial cells exposed to elevated hydrostatic pressure or stimulated ischemia secrete increased amounts of TNF- $\alpha$, subsequently leading to apoptotic death of cocultured retinal ganglion cells. This effect was attenuated by neutralizing antibodies against TNF- $\alpha$ [21]. Moreover, variations in the human TNFA gene promoter have been extensively studied for involvement in infectious diseases. SNPs at positions $-238,-276$, and -308 were analyzed for their possible association with diseases and their effects on promoter strength. The reported results are contradictory, and it is not yet clear if the SNPs under study are truly functional. To date, several reports have evaluated the association between TNFA promoter polymorphisms and risk for glaucoma. The results remain inconclusive [24-28]. However, such studies have not yet been undertaken in Indian POAG patients.

With this background, we investigated the involvement of COCH and TNFA in glaucoma pathogenesis in a cohort of east Indian POAG patients. Both genes were screened in 100 patients and controls for any possible causal variants in the coding region. Additionally, $1 \mathrm{~kb}$ of the $5^{\prime}$ upstream region of $\mathrm{COCH}$ was screened. Two common pSNPs $(-238 \mathrm{G} / \mathrm{A}$ and $-308 \mathrm{G} / \mathrm{A}$ ) in TNFA previously reported to be associated with POAG in different populations were also examined in a cohort of 285 patients and 285 controls.

\section{Materials and Methods}

2.1. Selection of the Study Subjects. The study cohort consisted of 285 POAG patients and 285 ethnically matched controls. East Indian patients affected with POAG, with or without a positive family history, were recruited in this study from the Dristi Pradip eye clinic (Kolkata, India). Diagnosis involved clinical, ocular, and systemic examinations. Ocular examinations involved measurement of IOP by applanation tonometry (Goldmann). Gonioscopy by Goldmann 3-mirror gonioscope (Shaffer's grading) revealed the angles of the anterior chamber and it was also used for optic disc evaluation and fundoscopy. Optic disc was further evaluated with $+78 \mathrm{D}$ lens and visual field was assessed by Humphrey's automated perimeter.

The POAG suspect was confirmed by typical reproducible visual field changes, namely arcuate, Bjerrum, Seidel, paracentral, and annular scotoma and nasal steps. In addition, scanning laser polarimetry for RNFL analysis (nerve fiber indicator $>30$ ) was also used to confirm the observation. An increased IOP above $21 \mathrm{~mm}$ of $\mathrm{Hg}$, significant cupping of optic disc with or without peripapillary changes, and presence of an open angle of anterior chamber raised suspicion of POAG which was confirmed by typical reproducible visual field changes in automated perimetry test. Individuals with IOP less than $21 \mathrm{~mm}$ of $\mathrm{Hg}$ were also included, who had cupping of the optic disc and visual field changes characteristic of POAG. The IOP in each case was corrected for central corneal thickness (CCT). Individuals with any history of inflammation or ocular trauma (past and present) were excluded from this study. The age of patients at the time of diagnosis was $>35$ years (mean age \pm SD, 60.49 \pm 12.97 years).

The controls were recruited following a stringent set of criteria which include age $>40$ years (mean age $\pm \mathrm{SD}$, $54.67 \pm 11.27$ years), without any family history of glaucoma or ocular hypertension, IOP $<20 \mathrm{mmHg}$ in both eyes in at least the last two checkups, CCT greater than $500 \mu \mathrm{m}$ in both eyes, no visual field defect, normal scanning laser polarimeter parameters (i.e., a good yellowish bow type scan pattern, deviation map within normal limit, a good double hump pattern in conduction map), temporal-superior-nasalinferior-temporal (TSNIT) parameters within normal limit, Nerve Fibre Indicator ( $<30$ for both eyes), cup discs being physiological and similar in both eyes, cup to disc ratio $<0.5$, no defect in disc rim or margin, and no sphincter haemorrhage around the disc. Individuals with high myopia ( $>8$ diopter), hypertension and diabetes were excluded from the control group. The study protocol adhered to the tenets of the declaration of Helsinki and was approved by the Institutional Review Board.

2.2. Collection of Blood Samples and Genomic DNA Preparation. Eight milliliters of peripheral blood were collected with EDTA from the POAG patients and normal individuals with their written consent. Genomic DNA was prepared from fresh whole blood using the PAX gene blood DNA isolation kit (Qiagen, Hilden, Germany) according to the manufacturer's protocol. The DNA was dissolved in TE (10 mM Tris-HCl, 1 mM EDTA, pH 8.0).

\subsection{Polymerase Chain Reaction and DNA Sequencing.} Screening was done in patients and controls by polymerase chain reaction (PCR) and sequencing. PCR was carried out in a total volume of $20.0 \mu \mathrm{L}$ containing $80 \mathrm{ng}$ genomic DNA, $0.4 \mu \mathrm{M}$ of each primer, $10 \mu \mathrm{L}$ of $2 \mathrm{x}$ ex Prime Taq Premix (GeNet Bio, South Korea) with specific primers (primer sequences are available on request). Briefly, for $\mathrm{COCH}$, each 
exon was amplified with an initial denaturation at $94^{\circ} \mathrm{C}$ for $5 \mathrm{~min}$, followed by 35 cycles of denaturation at $94^{\circ} \mathrm{C}$ for $30 \mathrm{~s}$, annealing at the range of $58-64^{\circ} \mathrm{C}$ for $30 \mathrm{~s}$, and extension at $72^{\circ} \mathrm{C}$ for $30 \mathrm{~s}$. A final extension at $72^{\circ} \mathrm{C}$ for $5 \mathrm{~min}$ completed the reaction. For $\mathrm{COCH}$ promoter amplification all the conditions were constant except the annealing temperature (at $52^{\circ} \mathrm{C}$ ). For $T N F A$, being a small gene, all exons were amplified in a single PCR; briefly, an initial denaturation at $94^{\circ} \mathrm{C}$ for $5 \mathrm{~min}$, followed by 35 cycles of denaturation at $94^{\circ} \mathrm{C}$ for $45 \mathrm{~s}$, annealing at $68^{\circ} \mathrm{C}$ for $45 \mathrm{~s}$, and extension at $72^{\circ} \mathrm{C}$ for $3 \mathrm{~min}$. A final extension at $72^{\circ} \mathrm{C}$ for 5 min completed the reaction. For TNFA promoter SNPs [-308 G/A, (rs1800629) and $238 \mathrm{G} / \mathrm{A}$, (rs361525)] genotyping, a segment of promoter was also amplified with an initial denaturation at $94^{\circ} \mathrm{C}$ for $5 \mathrm{~min}$, followed by 35 cycles of denaturation at $94^{\circ} \mathrm{C}$ for $30 \mathrm{~s}$, annealing at $53^{\circ} \mathrm{C}$ for $30 \mathrm{~s}$, and extension at $72^{\circ} \mathrm{C}$ for $45 \mathrm{~s}$. A final extension at $72^{\circ} \mathrm{C}$ for $5 \mathrm{~min}$ completed the reaction. All PCR products were detected on a $1.5 \%$ agarose gel with ethidium-bromide staining. Sequencing was done using the BigDye termination chemistry (version 3.1) in an ABI 3130XL capillary DNA sequencer (Applied Biosystems, Foster City, CA, USA) following manufacturer's protocol.

2.4. Sequencing, Bioinformatics, and Statistical Analysis. The sequences obtained from the patients were compared with the wild type sequence by NCBI nucleotide blast online software (http://blast.ncbi.nlm.nih.gov/Blast.cgi). In addition, the chromatograms were critically examined for any "double peak" that would identify the heterozygous alleles. Haplotypes and their frequencies were calculated for comparison between patients and controls using Haploview 4.1 software (http://www.broad.mit.edu/mpg/haploview). The allele frequencies of the SNP and haplotypes were compared between patients and controls using contingency chi square test $(95 \%$ CI). TFSEARCH (version 1.3) (http://www.cbrc.jp/research/db/TFSEARCH.html) was used to predict the transcription factor binding sites with default threshold score 85.0.

\section{Results}

We screened all 12 exons, adjoining splice junctions and $1 \mathrm{~kb}$ of the upstream regulatory region of $\mathrm{COCH}$ in $100 \mathrm{POAG}$ patients but did not find any variant in the gene that could be suspected as a mutation with the potential of causing POAG. Instead we detected a large number of SNPs, most of which are reported in dbSNP. These include 7 SNPs in the $5^{\prime}$ upstream region of the gene, 5 in the introns, 1 in exon 11 (Thr352Ser) and one in the $3^{\prime}$ UTR. Two of the SNPs $(-450 \mathrm{C} / \mathrm{T}$ and $-79 \mathrm{G} / \mathrm{C})$ detected in the $5^{\prime}$ upstream region are novel (Figures 1 and 2 ). The frequencies of the SNPs in our cohort were different for some variants, which is likely due to differences in the populations genotyped (Table 1). The variant $-450 \mathrm{C} / \mathrm{T}$ was detected in 3 patients and $-79 \mathrm{G} / \mathrm{C}$ in a single patient. However, $-450 \mathrm{C} / \mathrm{T}$ was also detected in 2 controls out of 100. In silico analysis of the novel changes revealed potential binding sites for multiple transacting factors. The $-79 \mathrm{G} / \mathrm{C}$ change leads to abolition of
CREB (cAMP response element-binding factor) binding site (TF search score 87.7), and $-450 \mathrm{C} / \mathrm{T}$ leads to gain of a binding site for Sp1 (specificity protein 1) (TF search score 87.7 ) and E2F (TF search score 86.2). The other five reported SNPs in the $5^{\prime}$ upstream region of $\mathrm{COCH}$ (Table 1 ) did not reveal any changes in the binding sites of transacting elements except one (rs8015095, T/G), which leads to abolition of the GR (Glucocorticoid receptor) binding site (TF search score 85.4). However, all of this bioinformatics-derived information is subject to experimental verification.

We detected only four SNPs in TNFA, located in the introns and UTRs, with frequencies different from those reported in dbSNP, possibly due to differences in the populations genotyped (Table 2). We genotyped two SNPs of TNFA [-308 G/A, (rs1800629) and $-238 \mathrm{G} / \mathrm{A},($ rs361525)] that are reported to be associated with different disorders including POAG in our patient and control cohorts. However, no significant association was observed with either of the SNPs $(P$ value $>0.05)$, neither in the allelic nor in the genotypic context (Tables 3 and 4). No significant association was found even after dividing the patients groups according to the presenting IOP ( $\geq 21 \mathrm{~mm}$ of $\mathrm{Hg}$ or $<21 \mathrm{~mm}$ of $\mathrm{Hg}$ ). None of the three different haplotypes, defined based on these two SNPs, showed any significant association with POAG (Table 5).

\section{Discussion}

In the present study, we screened the coding region of $\mathrm{COCH}$ and TNFA for the presence of disease causing mutations in East Indian POAG patient cohort. In addition, the $5^{\prime}$ upstream region of $\mathrm{COCH}$ was also analyzed for any potential disease causing regulatory variants. Two promoter SNPs ( $-308 \mathrm{G} / \mathrm{A}$ and $-238 \mathrm{G} / \mathrm{A})$ of TNFA were also genotyped in an additional 570 POAG patients and controls for their possible association with POAG.

Although $\mathrm{COCH}$ mutations have only been associated with DFNA9 so far, a gene linked to hearing loss disorder [1316], Cochlin deposits were detected in glaucomatous TM as well as DBA/2J glaucomatous mouse TM but not in normal controls [14]. Glaucomatous TM from older patients was also found to contain higher levels of Cochlin due to transcriptional upregulation [13, 29]. A recent report showed that overexpression and downregulation of Cochlin increases and decreases IOP, respectively, a potential risk factor of POAG [30]. Cochlin expression in glaucomatous TM (versus lack of expression in controls) suggests a potential release from "gene silencing" in the glaucomatous cases due to overexpression of other proteins. To understand the molecular basis of Cochlin expression in glaucomatous TM, we wanted to assess potential genetic variants in $\mathrm{COCH}$ in the POAG patient cohort, especially in the regulatory region of the gene. We did not find any mutations in the coding region of $\mathrm{COCH}$. However, we did identify two novel variants in the $5^{\prime}$ upstream region of the $\mathrm{COCH}$ gene $(-450 \mathrm{C} / \mathrm{T}$ and $-79 \mathrm{G} / \mathrm{C})$, which, upon in silico analysis, were found to alter the binding pattern of the transcription factors to the promoter region. These preliminary results are consistent with the reported alteration in $\mathrm{COCH}$ expression in the glaucomatous condition. In a 


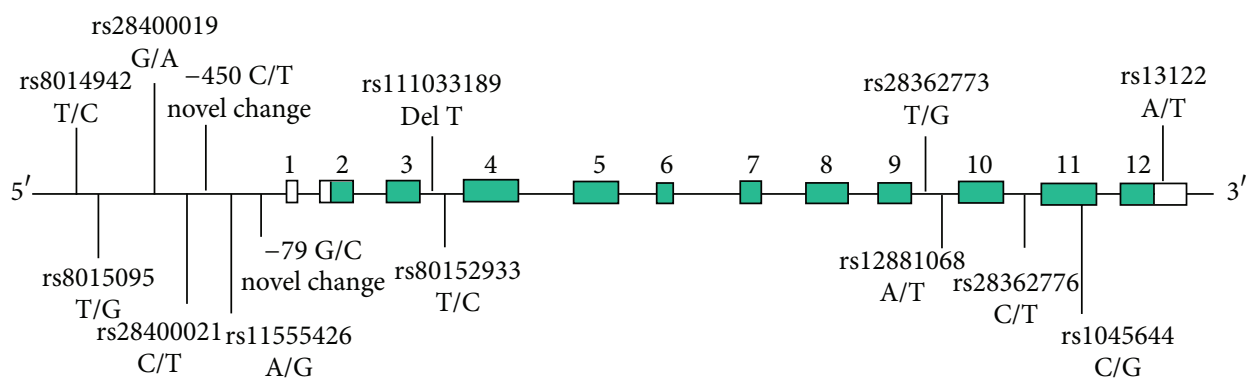

Cochlin $(\mathrm{COCH})$

(a)

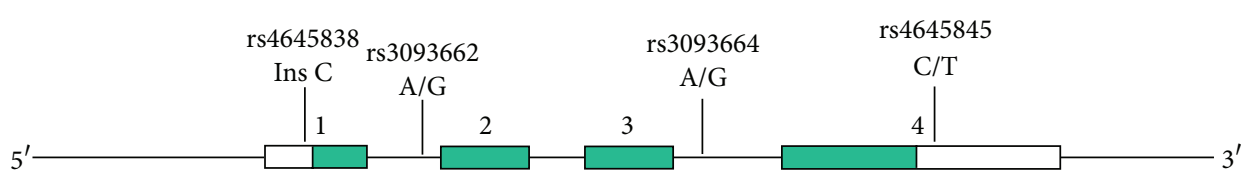

TNF- $\alpha(T N F A)$

Coding region

UTR

(b)

FIGURE 1: Schematic representation of $\mathrm{COCH}$ and TNFA genes with the location of SNPs and novel changes identified in the study. The sizes of exons and introns shown in the illustration are not according to scale.

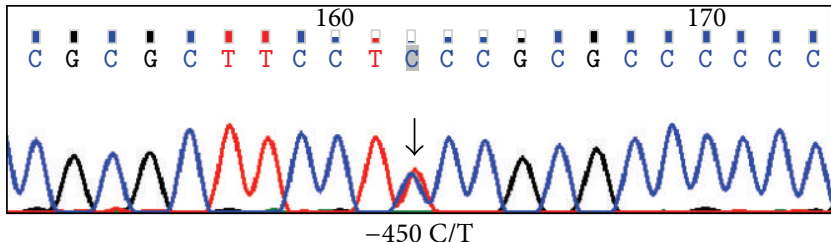

(a)

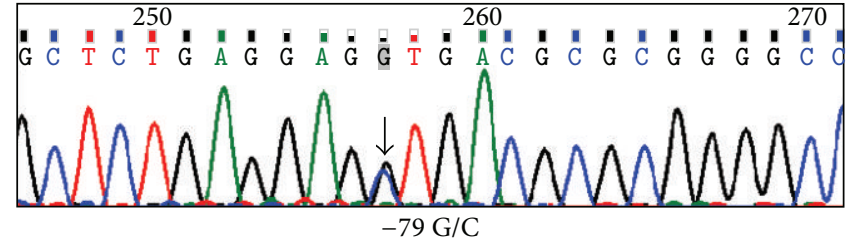

(b)

FIGURE 2: Representative chromatograms of the novel changes found in $\mathrm{COCH}$ screening. (a) $-450 \mathrm{C} / \mathrm{T}$ change, found in three patients and two controls; (b) $-79 \mathrm{G} / \mathrm{C}$ change, found in one patient only.

similar study, Pertz et al. examined 190 glaucoma patients and did not find any potential disease causing variants in $\mathrm{COCH}$ except for one reported coding polymorphism (Thr352Ser), two synonymous variants (Phe389Phe and Asp423Asp), and an intronic variant (IVS4-8A > G). But, this study did not look for any potential regulatory region variants in the patient population [31].

Although the in silico analysis of the promoter variants identified in our study suggests a potential role in $\mathrm{COCH}$ expression, in vitro experiments using a reporter gene assay need to be executed to get unequivocal evidence to confirm the prediction. A detailed survey of functional promoter elements, followed by assignment of promoter strength with different variants, will be required to assess the true functional potential of genomic variants in the regulatory region of $\mathrm{COCH}$. However, the overall effect of these variants on POAG pathogenesis is likely to be dependent on other factors that are yet to be learned through investigation.

Multiple studies to date have investigated the involvement of TNFA polymorphisms in POAG pathogenesis with variable outcomes [22, 24-28, 32-35]. We have analyzed the entire coding region of TNFA in our POAG patient cohort but failed to identify any disease causing mutation in this gene. In addition, two common promoter polymorphisms of TNFA ( $-238 \mathrm{G} / \mathrm{A}$ and $-308 \mathrm{G} / \mathrm{A})$ were genotyped in 570 POAG patients and controls. Both pSNPs were reported to influence TNF- $\alpha$ production, however the reports are controversial. Lipopolysaccharide- (LPS-) stimulated whole blood cell cultures from subjects with the -308 GA genotype were found to produce significantly higher levels of TNF- $\alpha$ compared to subjects carrying the -308 GG genotype [36, 37]. Also, the $-238 \mathrm{GG}$ genotype was reported to produce higher levels of TNF- $\alpha$ in LPS-stimulated whole blood cell cultures [38]. However, subsequent studies failed to replicate these observations [38-40]. Our study did not find any association of these two polymorphisms with the POAG patient cohort. It is worth mentioning here that although the $-238 \mathrm{G} / \mathrm{A}$ polymorphism was never found to be associated with POAG, an increased prevalence of the TNFA $-308 \mathrm{~A}$ allele is reported in POAG patient cohorts from China, 
TABLE 1: Variants identified in $\mathrm{COCH}$.

\begin{tabular}{|c|c|c|c|}
\hline SNP ID & Location & Minor allele frequency (db SNP*) & $\begin{array}{l}\text { Minor allele frequency } \\
\text { in patients }\end{array}$ \\
\hline rs111033189 del T & Intron 3 & NA & 0.05 \\
\hline rs80152933 T/C & Intron 3 & NA & 0.05 \\
\hline rs28362773 T/G & Intron 9 & 0.138 & 0.025 \\
\hline $\mathrm{rs} 12881068 \mathrm{~A} / \mathrm{T}$ & Intron 9 & 0.145 & 0.045 \\
\hline rs $28362776 \mathrm{C} / \mathrm{T}$ & Intron 10 & 0.022 & 0.04 \\
\hline rs1045644 C/G & Exon 11 (Thr352Ser) & 0.467 & 0.15 \\
\hline $\mathrm{rs} 13122 \mathrm{~A} / \mathrm{T}$ & $3^{\prime}$ UTR & 0.175 & 0.01 \\
\hline rs8014942 C/T & $5^{\prime}$ upstream region & 0.4886 & 0.16 \\
\hline rs8015095 T/G & $5^{\prime}$ upstream region & 0.197 & 0.05 \\
\hline rs $28400019 \mathrm{G} / \mathrm{A}$ & $5^{\prime}$ upstream region & 0.0847 & 0.03 \\
\hline rs $28400021 \mathrm{C} / \mathrm{T}$ & $5^{\prime}$ upstream region & 0.2381 & 0.24 \\
\hline$-450 \mathrm{C} / \mathrm{T}$ (novel change) & $5^{\prime}$ upstream region & NA & $\begin{array}{c}0.015 \\
(0.01 \text { in control })\end{array}$ \\
\hline rs11555426 G/A & $5^{\prime}$ upstream region & 0.10032 & 0.05 \\
\hline-79 G/C (novel change) & $5^{\prime}$ upstream region & NA & $\begin{array}{c}0.005 \\
\text { (not detected in control) }\end{array}$ \\
\hline
\end{tabular}

${ }^{*}$ http://www.ncbi.nlm.nih.gov/projects/SNP/.

TABLE 2: Variants identified in TNFA.

\begin{tabular}{lccc}
\hline SNP ID & Location & Minor allele frequency $\left(\mathrm{db} \mathrm{SNP}{ }^{*}\right)$ & Minor allele frequency in patients \\
\hline rs4645838 ins C & $5^{\prime}$ UTR & NA & 0.02 \\
rs3093662 A/G & Intron 1 & 0.079 & 0.01 \\
rs3093664 A/G & Intron 3 & 0.075 & 0.005 \\
rs4645845 C/T & $3^{\prime}$ UTR & 0.001 & 0.02 \\
\hline
\end{tabular}

${ }^{*}$ http://www.ncbi.nlm.nih.gov/projects/SNP/.

TABLE 3: Allele frequency distribution of two SNPs of TNFA promoter in patients and controls.

\begin{tabular}{lcccrr}
\hline SNP & Allele & Allele frequency in patients & Allele frequency in controls & $P$ value & OR $(95 \%$ CI $)$ \\
\hline \multirow{2}{*}{ rs361525 (-238 G/A) } & G & $0.897(481)$ & $0.912(469)$ & 0.406 & $1.192(0.772-1.840)$ \\
& A & $0.103(55)$ & $0.088(45)$ & 0.406 & $0.839(0.543-1.295)$ \\
\hline \multirow{2}{*}{ rs1800629 (-308 G/A) } & G & $0.957(513)$ & $0.955(491)$ & 0.884 & $1.045(0.557-1.960)$ \\
& A & $0.043(23)$ & $0.045(23)$ & 0.884 & $0.957(0.510-1.796)$ \\
\hline
\end{tabular}

TABLE 4: Genotype frequency distribution of two SNPs of TNFA promoter in patients and controls.

\begin{tabular}{lccccc}
\hline SNP & Genotype & Genotypic frequency in patients & Genotypic frequency in controls & $P$ value & OR (95\% CI) \\
\hline \multirow{2}{*}{ rs361525 (-238 G/A) } & GG & 0.81 & 0.833 & 0.567 & $0.855(0.533-1.370)$ \\
& GA & 0.175 & 0.16 & 0.712 & $1.120(0.619-1.818)$ \\
& AA & 0.015 & 0.007 & 0.686 & $1.932(0.302-15.301)$ \\
\hline \multirow{2}{*}{ rs1800629 (-308 G/A) } & GG & GA & 0.918 & 0.911 & 0.876 \\
& AA & 0.078 & 0.089 & 0.753 & $0.865(0.572-2.112)$ \\
& & 0.004 & 0 & - & - \\
\hline
\end{tabular}

TABLE 5: Haplotype frequency distribution of two SNPs of TNFA promoter in patients and controls.

\begin{tabular}{lcccc}
\hline Haplotype & Haplotype frequency in patients & Haplotype frequency in controls & $P$ value & OR (95\% CI $)$ \\
\hline G-G & 0.857 & 0.868 & 0.72 & $0.923(0.639-1.332)$ \\
G-A & 0.1 & 0.088 & 0.458 & $1.197(0.772-1.856)$ \\
A-G & 0.04 & 0.045 & 0.763 & $0.874(0.465-1.640)$ \\
\hline
\end{tabular}


Austria, Iran, and Turkey [24-26, 28, 32-35, 41]. However, a recent metaanalysis from 7 different reports from different populations did not identify any association of the $-308 \mathrm{G} / \mathrm{A}$ SNP with POAG [28]. Interestingly POAG patients were found to have higher level of TNF- $\alpha$ in the aqueous humor of their eyes [42], but the question of whether it is a cause or an epiphenomenon of the disease still remains to be answered.

\section{Conclusions}

To our knowledge, this is the first effort to ascertain the involvement of $\mathrm{COCH}$ and TNFA in an Indian POAG patient cohort. Our screening results suggested that $\mathrm{COCH}$ and TNFA genes are not associated with POAG pathogenesis in at least an East Indian POAG cohort. However, considering the minor contribution of each of the POAG loci identified so far to glaucoma pathogenesis, a screening effort in a much larger cohort from different regions of India could truly reflect the state of association of $C O C H$ and TNFA with POAG.

\section{Conflict of Interests}

The authors have declared that no conflict of interests exists.

\section{Acknowledgments}

The authors are thankful to the donors who participated in this study, to Dr. Keya Sen for helping with clinical evaluation of patients along with Dr. A. Sen, and Ms Ananya Ray (University of Wisconsin, Madison, WI USA) for helping with language correction of the paper. This study was supported by grants SIP-007, MLP-0016, and NWP 004 from the Council of Scientific and Industrial Research (CSIR), India. S. M. and S. C. were supported by fellowships from CSIR.

\section{References}

[1] D. Pascolini and S. P. Mariotti, "Global estimates of visual impairment: 2010," British Journal of Ophthalmology, vol. 96, no. 5, pp. 614-618, 2012.

[2] D. Banerjee, A. Bhattacharjee, A. Ponda, A. Sen, and K. Ray, "Comprehensive analysis of myocilin variants in east Indian POAG patients," Molecular Vision, vol. 18, pp. 1548-1557, 2012.

[3] K. Ray and S. Mookherjee, "Molecular complexity of primary open angle glaucoma: current concepts," Journal of Genetics, vol. 88, no. 4, pp. 451-467, 2009.

[4] M. Gemenetzi, Y. Yang, and A. J. Lotery, "Current concepts on primary open-angle glaucoma genetics: a contribution to disease pathophysiology and future treatment," Eye, vol. 26, no. 3, pp. 355-369, 2012.

[5] J. L. Wiggs, "The cell and molecular biology of complex forms of glaucoma: updates on genetic, environmental, and epigenetic risk factors," Investigative Ophthalmology and Visual Science, vol. 53, no. 5, pp. 2467-2469, 2012.

[6] J. H. Fingert, "Primary open-angle glaucoma genes," Eye, vol. 25, no. 5, pp. 587-595, 2011.

[7] K. N. Rao, S. Nagireddy, and S. Chakrabarti, "Complex genetic mechanisms in glaucoma: an overview," Indian Journal of Ophthalmology, vol. 59, no. 1, pp. S31-S42, 2011.
[8] E. M. Stone, J. H. Fingert, W. L. M. Alward et al., "Identification of a gene that causes primary open angle glaucoma," Science, vol. 275, no. 5300, pp. 668-670, 1997.

[9] T. Rezaie, A. Child, R. Hitchings et al., "Adult-onset primary open-angle glaucoma caused by mutations in optineurin," Science, vol. 295, no. 5557, pp. 1077-1079, 2002.

[10] S. Monemi, G. Spaeth, A. DaSilva et al., "Identification of a novel adult-onset primary open-angle glaucoma (POAG) gene on 5q22.1," Human Molecular Genetics, vol. 14, no. 6, pp. 725733, 2005.

[11] F. Pasutto, T. Matsumoto, C. Y. Mardin et al., "Heterozygous NTF4 mutations impairing neurotrophin-4 signaling in patients with primary open-angle glaucoma," American Journal of Human Genetics, vol. 85, no. 4, pp. 447-456, 2009.

[12] F. Pasutto, K. E. Keller, N. Weisschuh et al., "Variants in ASB10 are associated with open-angle glaucoma," Human Molecular Genetics, vol. 21, no. 6, Article ID ddr572, pp. 1336-1349, 2012.

[13] S. K. Bhattacharya, N. S. Peachey, and J. W. Crabb, "Cochlin and glaucoma: a mini-review," Visual Neuroscience, vol. 22, no. 5, pp. 605-613, 2005.

[14] S. K. Bhattacharya, E. J. Rockwood, S. D. Smith et al., "Proteomics reveal Cochlin deposits associated with glaucomatous trabecular meshwork," The Journal of Biological Chemistry, vol. 280, no. 7, pp. 6080-6084, 2005.

[15] R. Picciani, K. Desai, J. Guduric-Fuchs, T. Cogliati, C. C. Morton, and S. K. Bhattacharya, "Cochlin in the eye: functional implications," Progress in Retinal and Eye Research, vol. 26, no. 5, pp. 453-469, 2007.

[16] S. K. Bhattacharya, S. P. Annangudi, R. G. Salomon, R. W. Kuchtey, N. S. Peachey, and J. W. Crabb, "Cochlin deposits in the trabecular meshwork of the glaucomatous DBA/2J mouse," Experimental Eye Research, vol. 80, no. 5, pp. 741-744, 2005.

[17] S. Green, A. Dobrjansky, and E. A. Carswell, "Partial purification of a serum factor that causes necrosis of tumors," Proceedings of the National Academy of Sciences of the United States of America, vol. 73, no. 2, pp. 381-385, 1976.

[18] S. A. Bopegamage and A. Petrovičová, “Tumour necrosis factor alfa and glucose levels in sera of mice infected with coxsackie B4 and A7 viruses," Acta Virologica, vol. 42, no. 6, pp. 409-412, 1998.

[19] I. A. Cunliffe, P. S. Richardson, R. C. Rees, and I. G. Rennie, "Effect of TNF, IL-1, and IL-6 on the proliferation of human Tenon's capsule fibroblasts in tissue culture," British Journal of Ophthalmology, vol. 79, no. 6, pp. 590-595, 1995.

[20] X. Yan, G. Tezel, M. B. Wax, and D. P. Edward, "Matrix metalloproteinases and tumor necrosis factor $\alpha$ in glaucomatous optic nerve head," Archives of Ophthalmology, vol. 118, no. 5, pp. 666$673,2000$.

[21] G. Tezel, "TNF- $\alpha$ signaling in glaucomatous neurodegeneration," Progress in Brain Research, vol. 173, pp. 409-421, 2008.

[22] G. Tezel, L. Y. Li, R. V. Patil, and M. B. Wax, "TNF- $\alpha$ and TNF$\alpha$ receptor-1 in the retina of normal and glaucomatous eyes," Investigative Ophthalmology and Visual Science, vol. 42, no. 8, pp. 1787-1794, 2001.

[23] G. Tezel and M. B. Wax, "Increased production of tumor necrosis factor- $\alpha$ by glial cells exposed to simulated ischemia or elevated hydrostatic pressure induces apoptosis in cocultured retinal ganglion cells," Journal of Neuroscience, vol. 20, no. 23, pp. 8693-8700, 2000.

[24] B. Bozkurt, L. Mesci, M. Irkec et al., "Association of tumour necrosis factor-alpha $-308 \mathrm{G} / \mathrm{A}$ polymorphism with primary 
open-angle glaucoma," Clinical \& Experimental Ophthalmology, vol. 40, no. 4, pp. e156-e162, 2012.

[25] B. J. Fan, K. Liu, D. Y. Wang et al., "Association of polymorphisms of tumor necrosis factor and tumor protein p53 with primary open-angle glaucoma," Investigative Ophthalmology and Visual Science, vol. 51, no. 8, pp. 4110-4116, 2010.

[26] H.-J. Lin, F.-J. Tsai, W.-C. Chen, Y.-R. Shi, Y. Hsu, and S.-W. Tsai, "Association of tumour necrosis factor alpha -308 gene polymorphism with primary open-angle glaucoma in Chinese," Eye, vol. 17, no. 1, pp. 31-34, 2003.

[27] C. Wang, Y. Shen, L. Wei et al., "Polymorphism in the TNF- $\alpha(-$ 863) locus associated with reduced risk of primary open angle glaucoma," Molecular Vision, vol. 18, pp. 779-785, 2012.

[28] Q. Yu and Y. Yao, "A detailed meta-analysis shows no association between TNF- $\alpha$-308G/A polymorphism and different forms of glaucoma," Ophthalmic Research, vol. 47, no. 1, pp. 47-51, 2011.

[29] R. G. Picciani, A. Diaz, R. K. Lee, and S. K. Bhattacharya, "Potential for transcriptional upregulation of Cochlin in glaucomatous trabecular meshwork: a combinatorial bioinformatic and biochemical analytical approach," Investigative Ophthalmology and Visual Science, vol. 50, no. 7, pp. 3106-3111, 2009.

[30] M. Goel, A. E. Sienkiewicz, R. Picciani, J. Wang, R. K. Lee, and S. K. Bhattacharya, "Cochlin, intraocular pressure regulation and mechanosensing," PLoS ONE, vol. 7, no. 4, Article ID e34309, 2012.

[31] G. J. P. L.M. Pertz, E. Simpson, E. Bala et al., "Mutation screen in the COCH gene in 190 patients with glaucoma," Investigative Ophthalmology \& Visual Science, vol. 47, E-Abstract 210, 2006.

[32] G. Mossböck, M. Weger, M. Moray et al., "TNF- $\alpha$ promoter polymorphisms and primary open-angle glaucoma," Eye, vol. 20, no. 9, pp. 1040-1043, 2006.

[33] M. I. Khan, S. Micheal, N. Rana et al., "Association of tumor necrosis factor alpha gene polymorphism G-308A with pseudoexfoliative glaucoma in the Pakistani population," Molecular vision, vol. 15, pp. 2861-2867, 2009.

[34] G. Mossböck, W. Renner, Y. El-Shabrawi et al., “TNF- $\alpha-308$ $\mathrm{G}>\mathrm{A}$ and $-238 \mathrm{G}>\mathrm{A}$ polymorphisms are not major risk factors in Caucasian patients with exfoliation glaucoma," Molecular Vision, vol. 15, pp. 518-522, 2009.

[35] M. R. Razeghinejad, F. Rahat, and E. Kamali-Sarvestani, "Association of TNFA -308 G/A and TNFRI +36 A/G gene polymorphisms with glaucoma," Ophthalmic Research, vol. 42, no. 3, pp. 118-124, 2009.

[36] G. Bouma, J. B. A. Crusius, M. Oudkerk Pool et al., "Secretion of tumour necrosis factor $\alpha$ and lymphotoxin $\alpha$ in relation to polymorphisms in the TNF genes and HLA-DR alleles. Relevance for inflammatory bowel disease," Scandinavian Journal of Immunology, vol. 43, no. 4, pp. 456-463, 1996.

[37] H. Fujisawa, H. Ito, K. Saito, K. Ikeda, H. Nitta, and J. Yamashita, "Immunohistochemical localization of tissue-type plasminogen activator in the lining wall of chronic subdural hematoma," Surgical Neurology, vol. 35, no. 6, pp. 441-445, 1991.

[38] T. W. J. Huizinga, R. G. J. Westendorp, E. L. E. M. Bollen et al., "TNF- $\alpha$ promoter polymorphisms, production and susceptibility to multiple sclerosis in different groups of patients," Journal of Neuroimmunology, vol. 72, no. 2, pp. 149-153, 1997.

[39] M. Mycko, W. Kowalski, M. Kwinkowski et al., "Multiple sclerosis: the frequency of allelic forms of tumor necrosis factor and lymphotoxin-alpha," Journal of Neuroimmunology, vol. 84, no. 2, pp. 198-206, 1998.
[40] F. Pociot, S. D’Alfonso, S. Compasso, R. Scorza, and P. M. Richiardi, "Functional analysis of a new polymorphism in the human TNF $\alpha$ gene promoter," Scandinavian Journal of Immunology, vol. 42, no. 4, pp. 501-504, 1995.

[41] O. Tekeli, M. E. Turacli, Y. Egin, N. Akar, and A. H. Elhan, "Tumor necrosis factor alpha-308 gene polymorphism and pseudoexfoliation glaucoma," Molecular Vision, vol. 14, pp. 1815-1818, 2008.

[42] S. Balaiya, J. Edwards, T. Tillis, V. Khetpal, and K. V. Chalam, "Tumor necrosis factor-alpha (TNF- $\alpha$ ) levels in aqueous humor of primary open angle glaucoma," Clinical Ophthalmology, vol. 5, no. 1, pp. 553-556, 2011. 


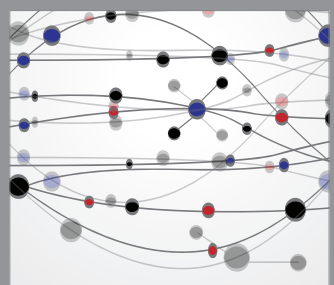

The Scientific World Journal
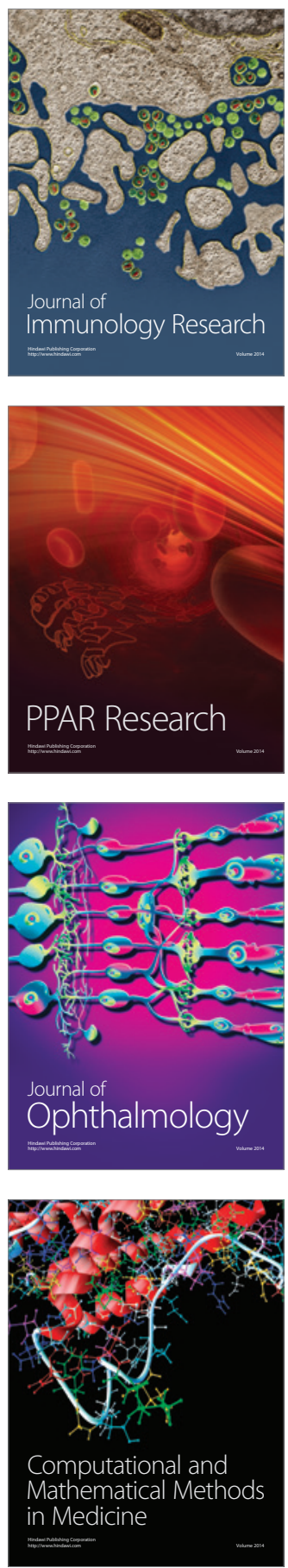

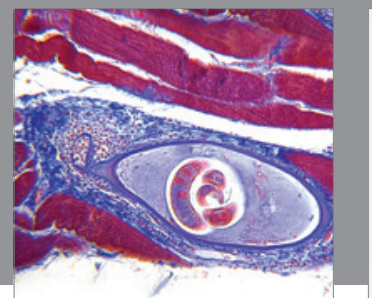

Gastroenterology

Research and Practice
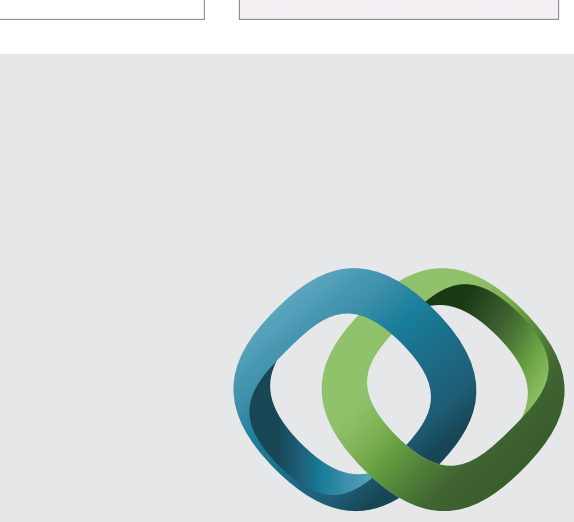

\section{Hindawi}

Submit your manuscripts at

http://www.hindawi.com
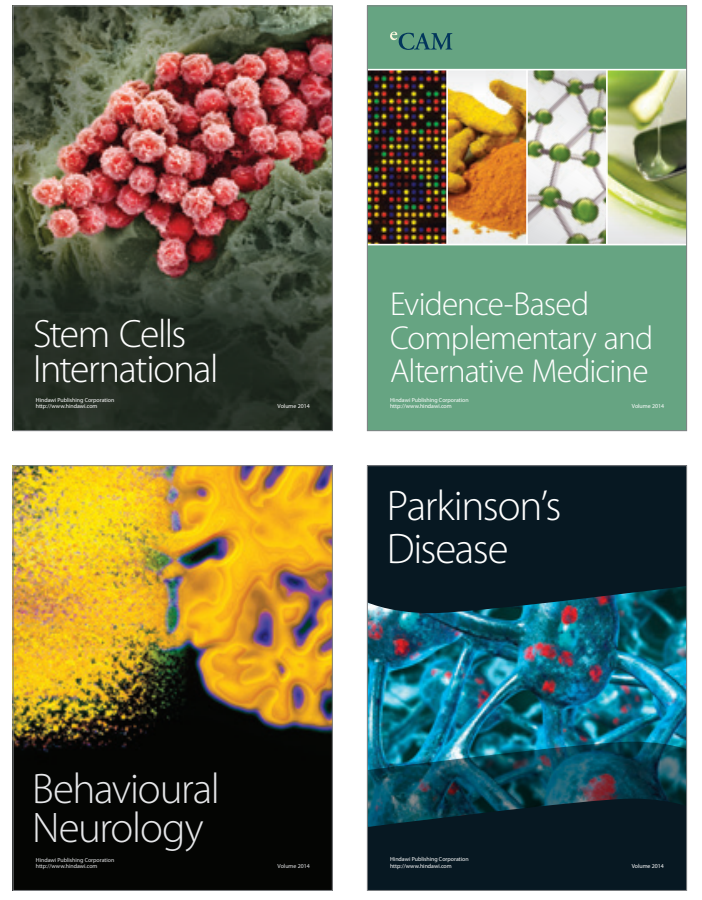
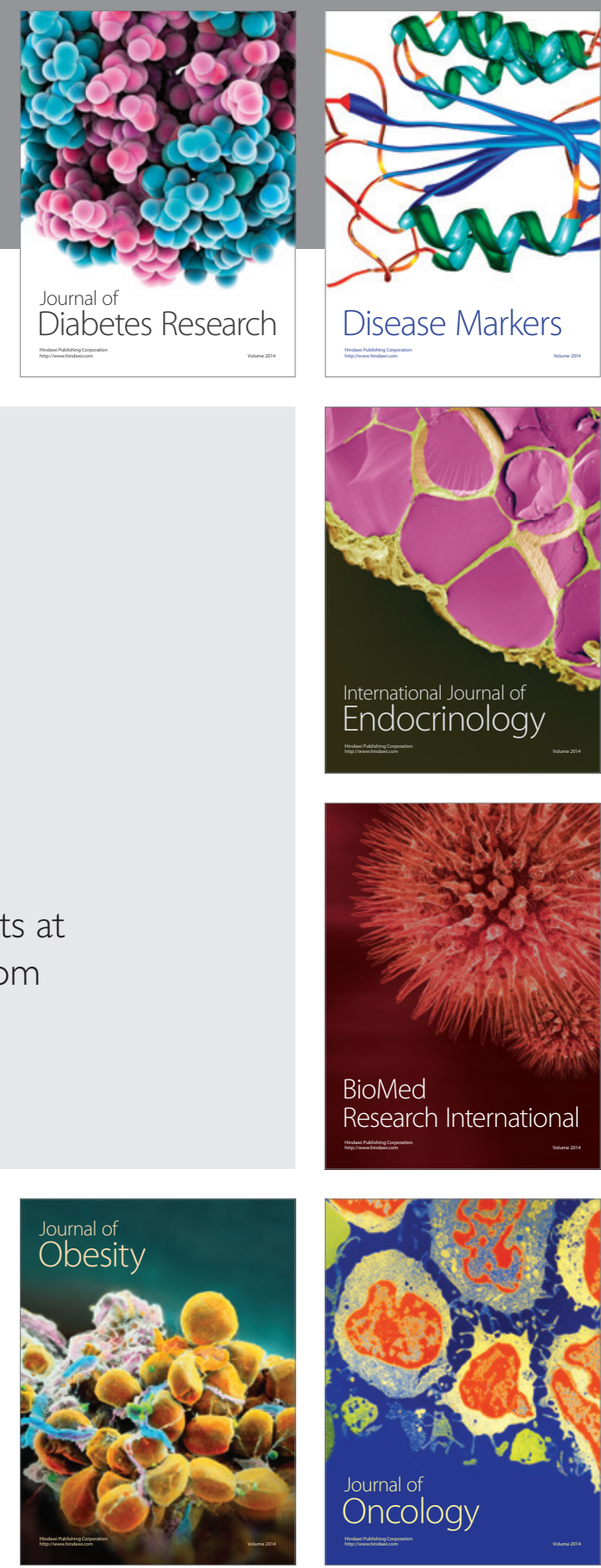

Disease Markers
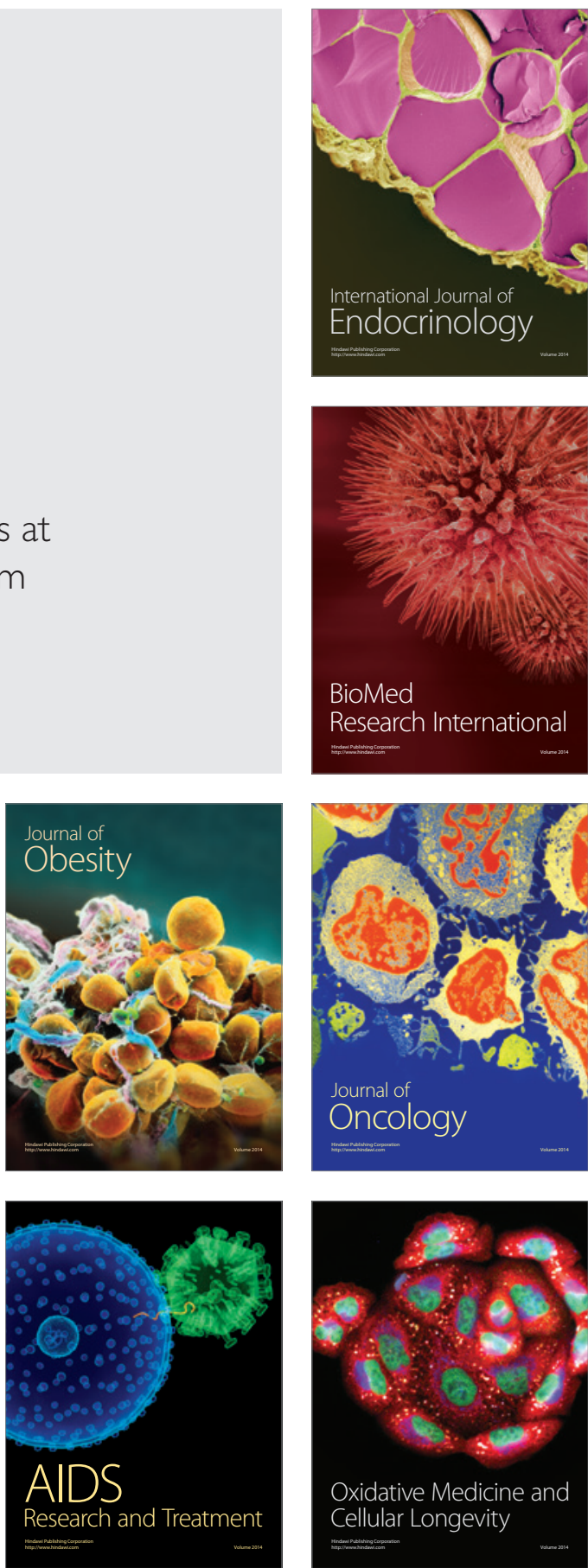